\title{
Physiological Alterations due to Acceleration and Gravity: A Brief Review of Recent Studies
}

\author{
Shibajyoti Banerjee ${ }^{1}$ \\ ${ }^{1}$ Electro-Technical University ETU LETI (Alumni), Kazan State Medical University
}

December 2, 2021

\begin{abstract}
Studies on physiological effects due to gravitation and acceleration have become a hot topic of research since the last century. Scientists and engineers have been putting their best efforts to excavate more about the physiological changes that occur in jet aircraft pilots and astronauts. This study focuses on a few prominent and recent observations related to the alterations of physiological functioning due to gravitational and acceleration forces.
\end{abstract}

\section{Hosted file}

new.pdf available at https://authorea.com/users/449237/articles/547800-physiologicalalterations-due-to-acceleration-and-gravity-a-brief-review-of-recent-studies 